\title{
Study on Coordinated Development of Ecological Environment Renovation and Natural Landscape Resources Development
}

\author{
Lin Zengxue ${ }^{1,2}$ \\ ${ }^{1}$ Central South University of Forestry and Technology \\ Changsha, China \\ ${ }^{2}$ Guilin Tourism University \\ Guilin, China
}

\begin{abstract}
With the increasing downward pressure on the economy, the contradiction between development and protection has become more prominent, the stability and service function of ecosystems in some areas have declined, and the awareness of ecological and environmental protection in some areas is weakening, which further increases the difficulty of promoting environmental governance and quality improvement as a whole. During the 13th Five-Year Plan period, ecological and environmental protection faces important strategic opportunities the construction of ecological civilization has become a national strategy. Therefore, the improvement of ecological environment should be combined with eco-tourism, so as to strengthen the protection of ecological environment, enhance the function of ecological security barrier, build ecological product supply area, improve the efficiency of environmental resources utilization, accelerate the industrial upgrading, and realize the win-win combination of ecological environment improvement and natural scenery resources development.
\end{abstract}

Keywords-Methods of ecological environment renovation; The development of nature's landscape resources

\section{INTRODUCTION}

There are many ways to improve the ecological environment. In the past, when the idea of protecting the environment and caring for the earth had not been deeply rooted in people's minds, people only cared about getting rich for their own sake, even at the cost of destroying the environment by any means for the sake of money. Nowadays, the ecological environment is becoming more and more fragile, even affecting people's normal living conditions, so people finally began to pay attention to the protection of the environment and ecological environment renovation. But in the early years, people were still simply renovating the ecological environment, the means were simple and the methods were stupid. It was not until recent years that the renovation of the ecological environment was combined with the exploitation of natural resources.

In China, in earlier years, China Carries out Reform and Opening-up, the economy has developed rapidly, but because the development of science and technology in China was relatively backward compared with some developed countries in the West, most of the means by which the Chinese people want to get rich are still relatively backward. People are scrambling to open factories, such as tanneries, brick mills, flour mills, coal mills and so on, which are very popular in almost every county and township. These factories are characterized by lower costs, There is no technical content, people can use fairly primitive means to produce goods, But it will have a series of bad effects on the environment, for example, coal mills and flour mills will produce a lot of dust flowing into the air every day, and in earlier years no coal desulfurization and other technologies are used, directly leading to the acidification of rainwater in its production, endangering the local ecological environment. In addition to these lower-level factories, there are also factories with relatively high economic incomes, which are used to produce heavy industrial products, but such relatively backward level of production has led to serious environmental damage. Worse still, they make money in the most traditional way, like animals hunting, but they are not hunting ordinary animals in the mountains, but those national protected animals in violation of the law, resulting in a serious reduction in the diversity of biological species; every day many biological species are facing the risk of disappearing from the planet. The Earth can provide us with a stable and harmonious living environment because of the diversity of biological species, but with the disappearance of more and more biological species, the earth we depend on can no longer provide us with harmonious and stable living conditions. Up to now, the renovation of ecological environment has reached such extent that some measures must be taken immediately. However, because of the high cost of ecological environment renovation, many enterprises and factories, for their own interests, cannot accept the methods of purchasing modern production machines or investing capital to improve and protect the natural environment. Therefore, according to the current specific situation, ecological environment renovation is still not fully implemented on every inch of destroyed land, and as for ecological environment renovation, it still needs us all to work together. Although the renovation of some areas has been put on the agenda by the local government, but it has not fully shouldered the responsibility, the specific renovation plan is still open to question, but also there are a series of problems such as incomplete renovation plan, insufficient investment and so on. 


\section{PRACTICAL EXAMPLES OF COORDINATED DEVELOPMENT OF ECOLOGICAL ENVIRONMENT RENOVATION AND LANDSCAPE RESOURCES EXPLOITATION}

At present, many scientist in the field of environmental protection have worked out a numb of schemes for ecological environment renovation, but not all of them get effective feedback, of which the most satisfying method to the scientist as well as the most satisfying method to the masses of the people is still a scheme combining the exploitation of natural scenery resources with the renovation of the local ecological environment; As for this scheme, according to the characteristics of local ecological environment, as well as the local historical and cultural characteristics, while renovating the ecological environment, the tourism industry in these areas will be developed, which not only makes the local ecological environment be renovated, but also creates a new way for the local residents to get rich, at the same time, it can make the renovation of the ecological environment more thorough and achieve the best results.

\section{A. Case I: Renovation of Eco-tourism Resources in Guangxi}

With the development of tourism in Guangxi, the number of tourists is increasing rapidly. A large amount of domestic wastewater, waste gas and waste residue are discharged into the ecological protection zone, which greatly affects the growth and development of animals and plants. A large number of tourists gathered in the scenic spots, the tread on the land and some damage to the soil and vegetation will cause serious soil cementation, compaction, water infiltration decreasing, surface runoff increase, increase in soil erosion, thus affect in the growth of vegetation and damaging the scenic spots. As for tourism developed in the ecological protection zone, tourists will bring in a lot of pollutants when they enter, for example, the discarded garbage will affect the ecological environment of the protection zone. The construction of hotels, restaurants and other service facilities and other recreational facilities will inevitably destroy some surrounding landscapes, and destroy the vegetation on both sides of the road. Nowadays, in order to change this bad situation, Guangxi began to carry out the ecological environment renovation, their renovation method is to combine the ecological environment renovation with the development of natural scenery resources, reasonably plan the functional area, protect the core area, and develop the experimental area, buffer zone and core area. Adhere to the principle of sustainable utilization, earnestly protect biodiversity, strictly protect core areas, and refrain from opening tourism to the outside world. Conduct scientific research and production in the pilot area; Tourism business will be carried out in the tourist areas, and tourist spots and routes are strictly prohibited from being staggered with the core area. According to the actual situation, each protected area shall be divided into functional areas reasonably so as to give full play to its functions in protection, tourism, publicity and education, scientific research and production.

As a result, the coordinated development of ecological environment renovation and natural landscape resources has attracted a large number of tourists, Natural scenery resources have also been exploited, and the pressure brought to people's lives due to in the ecological environment renovation can also be compensated through the development of tourism, killing two birds with one stone, which will greatly change the local people's lives to a great degree.

\section{B. Case II: Construction of some of the most beautiful urban and rural areas}

In recent years, China has renovated many urban and rural areas, created some of the most beautiful villages and nature reserves. Eco-environmental renovation in some rural areas help people design ways of living that suit their natural resources and environment, for example, in mountainous areas, China will help locals create new ways of getting rich, rather than just ploughing the mountains and planting a single variety of crops. Local people can change the way of planting the single rice crop, instead they may develop fruit trees and animal husbandry, which will not only change the frequent occurrence of local debris flow and other natural disasters, so that the local ecological environment can be improved accordingly, but also increase the income of local residents. And because modern people live in cities for so long, there is a special yearning for nature, So when the fruit is ripe, you can promote people to go to the mountains to pick their own, thus attracting a large number of tourists; There are many people attracted to come, or pick fruit, or view the scenery, or relax, and after a long time, this place has become the tourist destination everyone longs for. Some villages in the Central Plains have also undergone ecological improvement, instead of the heavy use of pesticides, fertilizer and films commonly used by farmers in agriculture, farmers are taught with the appropriate agricultural planting expertise, and are guided to plant scientifically; At the same time the environment of these villages is rectified and beautified, which not only makes the local ecological environment be rectified, but also attracts a lot of people to visit the beautiful and natural living environment, so that the service industry of these towns has been greatly developed at the same time.

\section{METHODS OF COMBINING THE RENOVATION OF \\ ECOLOGICAL ENVIRONMENT WITH THE EXPLOITATION OF NATURAL LANDSCAPE RESOURCES}

The above two cases show that the combination of the ecological environment renovation and the exploitation of natural scenery resources generates a good response, which also proves that the joint development of the ecological environment renovation and the exploitation of natural scenery resources is a very good method. But in different areas, the methods of renovating its ecological environment should also be different, and the renovation plan suitable for the local natural environment should be made according to the local conditions, so that these plans can not only help to improve the local ecological environment, but also make the local natural scenery resources be exploited to a certain extent. Of course, the development of natural scenery resources needs prerequisite conditions, some areas have the conditions for the development of tourism industry, while others are inadequate, so the development of natural scenery resources cannot be in mandatory manner, but should be appropriate. 


\section{A. Renovation of Some Natural Scenic Tourist Areas}

People's living conditions have improved markedly nowadays, more and more people prefer to travel and relax, This has exerted tremendous pressure on the ecological environment of some scenic tourist areas, In some tourist areas, in order to increase the turnover and attract more people every day, many man-made buildings have been built in the natural scenic tourist areas, including some hotels and playgrounds, which have brought great pressure to the local ecological environment. Some areas face the ecological environment protection pressure and are found with a series of environmental problems, and finally the only way is to spend a lot of manpower, material and financial resources to demolish these buildings. The stability of the ecological environment is more important to the natural scenery tourism area than to some ordinary areas, because these natural scenery tourism areas are relatively rich in biological resources, once the living environment of these organisms is destroyed, it is likely to cause the direct death of a large number of organisms in this tourism area. So for these areas, its development must always take into account the stability of the local ecological environment, and it can not only focus on the development of tourism industry. In the development of the tourism industry, it is necessary to evaluate the ecological endurance of the natural scenery tourism. The construction of buildings and the development of tourism in this area should be within the scope of ecological endurance to ensure the stability of the local ecological environment. It is necessary to renovate the ecoenvironment in some unqualified tourist areas, so that the local natural scenery resources can be fully utilized and developed while the eco-environment is stable.

\section{B. Renovation and Development of Other Ordinary Areas}

For those areas that are not tourist sites, we can also renovate and transform them according to their own conditions. For those polluted rivers, while renovating the ecological environment, we should also exploit its natural landscape resources, build it into a park for everyone to play. River's ecological renovation is very necessary, as it is very helpful for people to improve the comfort of life. A place where there are rivers is often the place where the air humidity is often greater, as river can effectively help people to prevent a series of diseases, make people's lives more comfortable and healthy, more suitable for people's lives. But if the river is polluted, it will also make people's lives damaged to a certain extent, so the ecological renovation of the river is very important. In addition to river areas, there are also some places that depend on mountains, we can improve the local ecological environment which is fragile, with frequent floods and debris flows, as well as develop natural scenery resources in mountain area, such as the development of mountains into famous mountain climbing scenic spots, and so on. Some ordinary central plains areas can also achieve development relying on other local characteristics.

\section{CONCLUSIONS}

In short, if the ecological environment of a region is not stable, it is very necessary to carry out the corresponding renovation. If we can discover the local natural scenery resources in time for corresponding development and exploition while carrying out the ecological environment renovation, we can certainly achieve win-win results. The development of natural scenery resources can not only make the local resources not be wasted, but also make up for the cost of ecological environment renovation. Once a place becomes a natural scenery tourism area, it will bring people unpredictable income afterwards, so the coordinated development of ecological environment renovation and natural scenery resources development is a win-win thing.

\section{ACKNOWLEDGMENT}

Acknowledgements: First-class discipline of Guangxi province support project (Grant No. 2018 Tourism management).

Author: Lin Zengxue (1965- ), male, born in Cangzhou, Hebei Province, Central South University of Forestry and Technology Ph.D. Candidate. Working in Guilin Tourism University School of tourism, leisure and management. Research direction tourism ecological landscape.

\section{REFERENCES}

[1] Henan ZHOU. Research on Agro-ecological Environment and Sustainable Development [D], Bohai University, 2013

[2] Shien AO. Research on the Protection and Governance of Agricultural Ecological Environment - Environment and Life [J]. Environment and Life, 2014.

[3] Zengxue LIN, Qunming ZHENG. Exploration on the Development Characteristics of Japanese Forest Bath Base [J]. Social Scientist, 2013 (06): 87-90 